\title{
Environmental Consequences of Rising Energy Use in China*
}

\author{
Warwick J. McKIBBIN† \\ Centre for Applied Macroeconomic Analysis, Research School of Pacific and Asian Studies, The Lowy Institute for \\ International Policy, and The Brookings Institution
}

\begin{abstract}
China is already the world's third largest energy producer and second largest energy consumer accounting for 10 percent of global energy use. This share is expected to rise to 15 percent by 2025 . Energy use in China has important environmental consequences which are explored in this paper. A range of policy options are also discussed. It is argued that each major environmental issue requires a policy response that is a mix of direct government intervention as well as market based incentives. In coming decades, the choices made by China of how to tackle the environmental consequences of expanding energy use will have important implications for China, Asia and the world.
\end{abstract}

Key words China, energy, environment, growth, policy

doi: $10.1111 / j .1748-3131.2006 .00017 . x$

\section{Introduction}

The emergence of China as an economic power has important implications for energy use and environmental outcomes at the local, regional and global levels. China is currently the world's third largest energy producer and the second largest energy consumer. ${ }^{1}$ As shown in Table 1, in 2002, China accounted for 10\% of world energy use and is projected by 2025 to account for $15 \%$ of global energy use. China is the world's largest coal producer accounting for $28 \%$ of world coal production and $26 \%$ of world coal consumption. China is the third largest consumer of oil and is estimated to have the world's sixth largest proven reserves of oil. China has roughly $9.4 \%$ of the world's installed electricity generation capacity (second only to the USA) and over the next three decades is predicted to be

${ }^{\star}$ Revised paper prepared for the Asian Economic Policy Review conference held in Tokyo on 22 October 2005. This paper draws on early research funded by the China Economic Research and Advisory Programme (CERAP). The author thanks Professor Kazuhiro Ueta, Professor Tatsuyoshi Saijo, editors of this journal and participants of the AEPR conference for helpful comments. The author also thanks Yan Yang for excellent research assistance and Dr Tingsong Jiang for insights from an earlier collaboration. The views expressed in the paper are those of the author and should not be interpreted as reflecting the views of the institutions with which the author is affiliated including the trustees, officers or other staff of the Australian National University, The Lowy Institute or The Brookings Institution.

†Correspondence: Warwick J. McKibbin, Centre for Applied Macroeconomic Analysis, Research School of Pacific and Asian Studies, Australian National University, ACT 0200, Australia. Email: warwick.mckibbin@anu.edu.au 
Table 1 Shares in global energy consumption and carbon dioxide emissions (\%)

\begin{tabular}{lrrrrrr}
\hline Region & 1990 & 2000 & 2001 & 2010 & 2015 & 2020 \\
\hline Energy consumption & & & & & & \\
$\quad$ China & 7.7 & 9.3 & 9.8 & 11.6 & 12.7 & 13.7 \\
$\quad$ Other developing countries & 17.9 & 24.3 & 24.6 & 25.7 & 26.5 & 27.2 \\
$\quad$ Eastern Europe/ Former Soviet Union & 21.9 & 13.1 & 13.2 & 12.5 & 12.4 & 12.4 \\
$\quad$ Industrialized countries & 52.5 & 53.4 & 52.4 & 50.2 & 48.4 & 46.7 \\
$\quad$ World total & 100.0 & 100.0 & 100.0 & 100.0 & 100.0 & 100.0 \\
Carbon dioxide emissions & & & & & & \\
$\quad$ China & 10.5 & 12.2 & 12.8 & 14.7 & 15.9 & 17.0 \\
$\quad$ Other developing countries & 18.3 & 25.0 & 25.4 & 26.4 & 27.1 & 27.7 \\
$\quad$ Eastern Europe/Former Soviet Union & 22.7 & 13.1 & 13.2 & 12.3 & 12.0 & 11.9 \\
$\quad$ Industrialized countries & 48.5 & 49.7 & 48.7 & 46.7 & 45.0 & 43.4 \\
$\quad$ World total & 100.0 & 100.0 & 100.0 & 100.0 & 100.0 & 100.0 \\
\hline
\end{tabular}

Source: Energy Information Administration (2004).

responsible for up to $25 \%$ of the increase in global energy generation. China's size and compositions of energy use is reflected in carbon dioxide emissions. China is estimated to emit $13 \%$ of global carbon emission from fossil fuels (second only to the USA) and this share is projected to rise to $18 \%$ by 2025 (see Table 1 and Figure 5). In an attempt to move away from fossil fuel reliance, China currently has plans for another thirty nuclear reactors in the next two decades to supplement the nine already existing (Department of Energy, 2004). It is estimated that China has the largest hydroelectric capacity in the world (largely in the south-west of the country), which currently generates $20 \%$ of Chinese electricity. The Three Gorges hydroelectric dam on the Yangtze River will be the world's largest power plant when completed around 2009. In March 2005, the National Development and Reform Commission (NDRC) approved the largest wind farm in Asia to begin construction in 2006. Although impressive in scale, the emergence of renewable energy will only slightly dent the overall dominance of coal in the foreseeable future in China. This means that China will need to respond to a range of environmental problems resulting from burning fossil fuels, such as air quality (including black carbon emissions), acid rain (from sulfur dioxide and nitrogen oxides emissions) and climate change (from carbon dioxide emissions).

Although China has for several decades started to address environmental problems, the focus on energy as a source of economic growth has dominated the energy debate in China. This is beginning to change as income levels in China make the environment a more important issue and as environmental quality continues to deteriorate.

This paper gives an overview of the environmental consequences of energy use in China with a focus on what responses might alleviate current and future problems. ${ }^{2}$ The first set of issues relate to how local action to reduce local environmental issues such as emissions of sulfur dioxide and black carbon can make an important contribution to regional problems such as acid rain, as well as global efforts to tackle greenhouse 
emissions. Importantly this action will likely have significant impacts on Chinese economic growth and the wellbeing of the Chinese people. A number of existing policies that China has already put in place to tackle local and regional environmental problems are also discussed. ${ }^{3}$ Other issues relate to rising energy use, rising greenhouse emissions and the implications for China of serious global climate change policy. This paper outlines a response to carbon dioxide emissions that could be implemented in China in coming years but has not yet entered the Chinese debate. This approach focuses on creating long-term property rights and clear incentives in pricing carbon emissions in an effort to reduce greenhouse gas emissions over time. It is in many ways similar to experiments already underway in China with trading sulfur emission permits. However, it is important to note that dealing with sulfur emissions is very different to dealing with carbon dioxide emissions. This difference is particularly important for China as a large country that has ratified the Kyoto Protocol ${ }^{4}$ and would be expected at some stage in the future to take on binding targets for carbon emissions or at least a commitment to some target. China has already shown a commitment to tackle local environmental problems with encouraging outcomes, but is there is still much to be done. ${ }^{5}$

This paper is structured as follows. Section 2 summarizes the history of energy use and projections out to 2020 of energy use in China, the environmental consequences of energy use are summarized in section 3, policy responses are considered in section 4 and conclusions are given in section 5 .

\section{Historical Experience and Projections of Energy Use}

The importance of China in world energy use is summarized in Table 1. In 2001 China accounted for $10 \%$ of world energy use (compared to the USA at $23 \%$ ) and $13 \%$ of global carbon dioxide emissions from fossil fuel use (compared to the USA at 23\%). Chinese gross domestic product (GDP) in 2003 is estimated in purchasing power parity (PPP) terms to be roughly $59 \%$ of the size of the USA (UNDP, 2004). This implies that although carbon emissions per unit of energy use are higher in China than in the USA, energy use per unit of GDP (in PPP terms) is slightly lower in China than in the USA. Most studies of energy intensity (i.e. energy use per unit of GDP) use market exchange rates for this comparison, which makes China look far more energy intensive. However, GDP measured at market exchange rates is inappropriate as a benchmark given the problems with comparing GDP across countries at different stages of development. ${ }^{6}$

Figure 1 shows the recent history of energy production and consumption in China. Energy demand and supply in China has been rising quickly: more than doubling between 1980 and 1996. In 1998, Chinese energy consumption began to outstrip Chinese energy production. Economic growth and the rising demand for energy in China is now spilling over into global energy prices far more importantly that it did before 2002.

Figure 2 clearly shows that Chinese energy supply has relied predominantly on large supplies of low cost coal (mainly located in the northern part of the country). China produces roughly $28 \%$ of global production of coal and consumes $26 \%$ of global production. Crude oil is the next largest source of energy supply followed by hydroelectricity, natural gas and nuclear energy. 


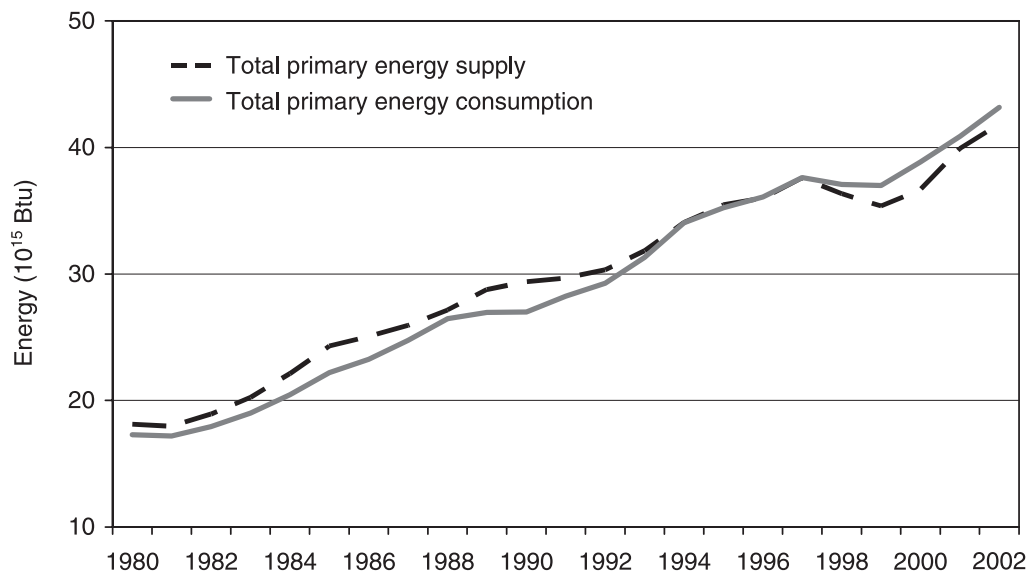

Figure 1 China's total energy consumption and supply, 1980-2002. Source: Energy Information Administration (2004).

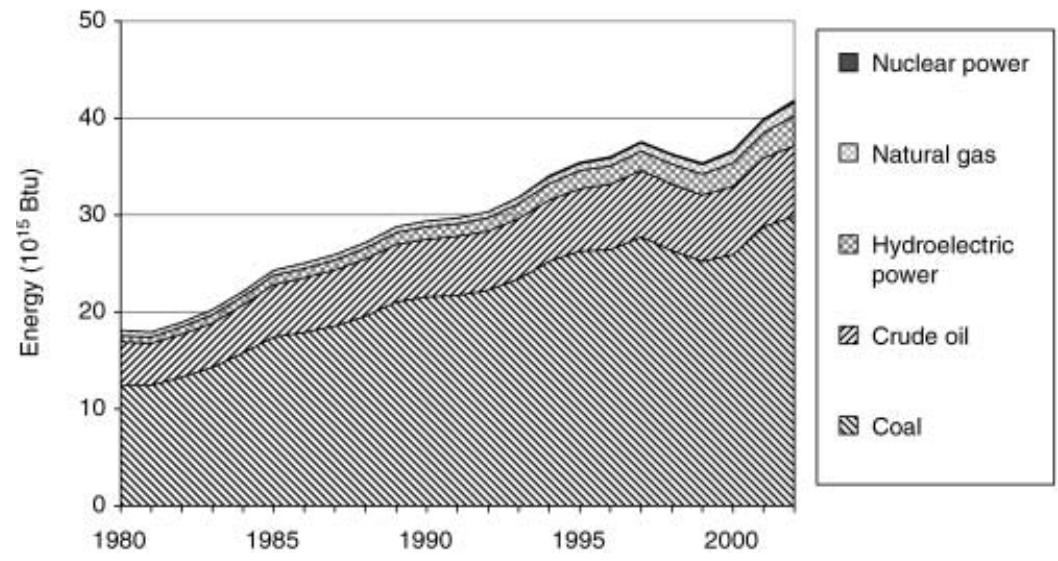

Figure 2 China's energy production by fuel type, 1980-2002. Source: Energy Information Administration (2004).

The sources of demand for energy in China for recent years are summarized in Table 2, which shows the decomposition by sector. Industry is overwhelmingly the largest user of energy amounting to $70 \%$ of the total in 2002 . This is followed by the household sector at $12 \%$ and transportation at only $7 \%$.

Projecting future energy use in China is very difficult. It is very tempting to base future projections on recent trends. However, as shown by Bagnoli et al. (1996) and McKibbin et al. (2004), overall economic growth is not the key determinant of energy use; the sources of economic growth are critical. A number of projections are available. The Energy Information Administration in their annual International Energy Outlook provides one source of projections. These are shown in Figure 3 for scenarios of high and low economic growth and a reference case. There is very little change in trend projected in these scenarios for 
Table 2 Total energy consumption by sector

\begin{tabular}{lrrrr}
\hline Sector & 1992 & 1996 & 2000 & 2002 \\
\hline Farming, forestry, animal husbandry, fishery \& water conservancy & 4.6 & 4.1 & 4.4 & 4.4 \\
Industry & 69.9 & 72.2 & 68.8 & 68.9 \\
Construction & 1.3 & 1.0 & 1.1 & 1.1 \\
Transportation, post and telecommunications service & 4.6 & 4.3 & 7.6 & 7.5 \\
Wholesale, retail trade and catering service & 1.3 & 1.6 & 2.2 & 2.3 \\
Others & 4.0 & 3.9 & 4.4 & 4.3 \\
Residential consumption & 14.3 & 12.7 & 11.4 & 11.51 \\
Total energy consumption & 100.0 & 100.0 & 100.0 & 100.0 \\
\hline
\end{tabular}

Source: National Bureau of Statistics (2003).

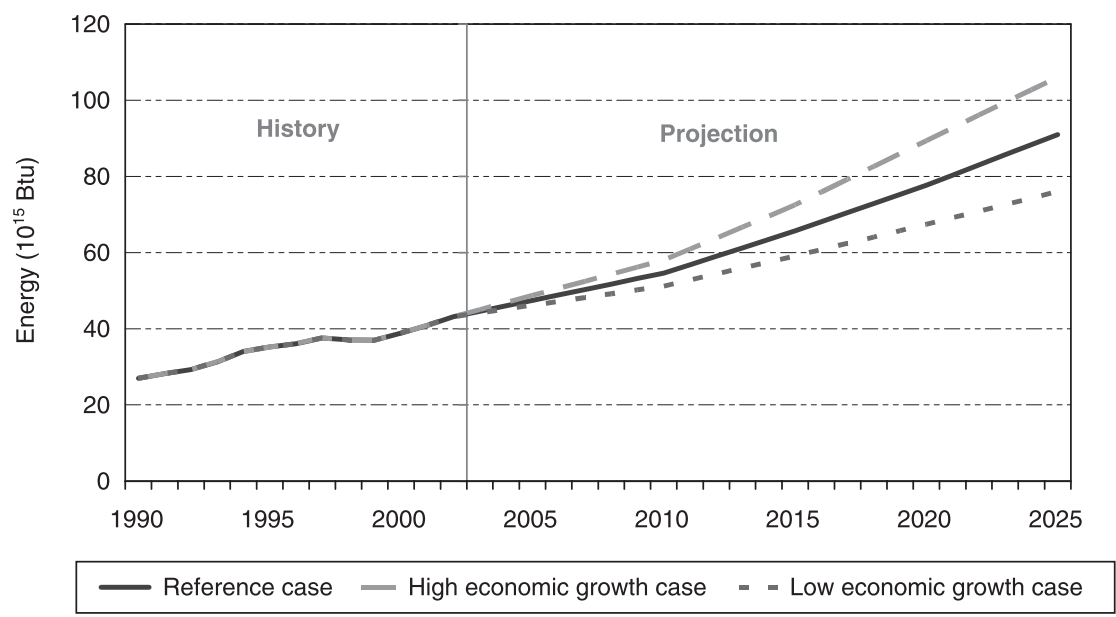

Figure 3 Projection of China's total energy consumption, 1990-2025. Source: Energy Information Administration (2004).

China compared to recent experience. Interestingly there is also little change in the real price of oil or any fossil fuels throughout the projection period in the International Energy Outlook. Figure 4 shows the breakdown of the overall energy projections into energy projections by generation source as predicted by the Energy Information Agency for natural gas, coal, petroleum and nuclear power generation in China from 1990 to 2025. These projections at the aggregate level and the composition of energy generation shows a continuation of recent rends at least out to 2010.

Under most scenarios, the emergence of China as a key supplier of energy and producer of energy is one of the most important issues in the debate over global energy use for the foreseeable future. As shown in the following sections, this is also a critical concern for environmental issues in China, Asia and globally. 

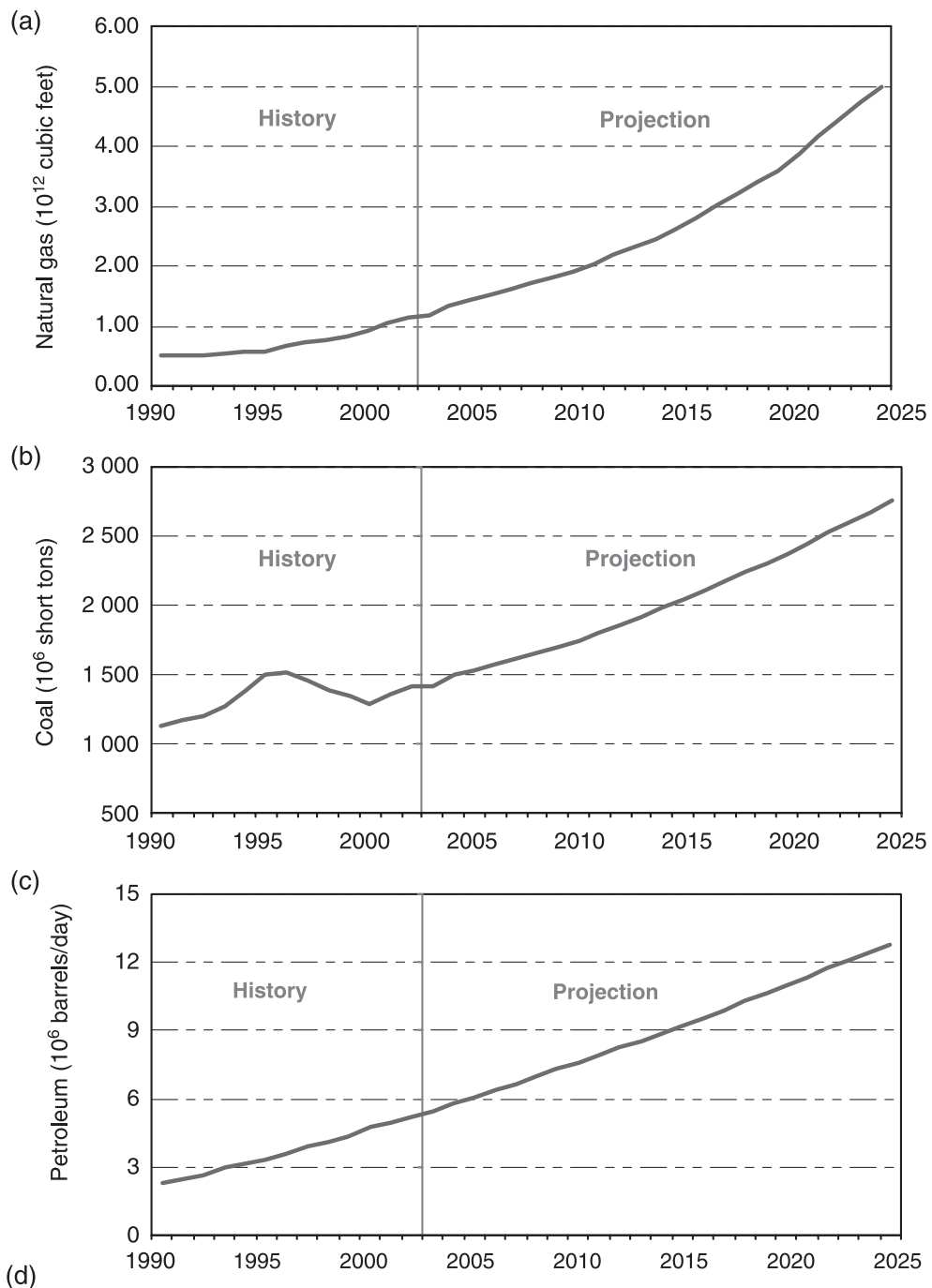

(d)

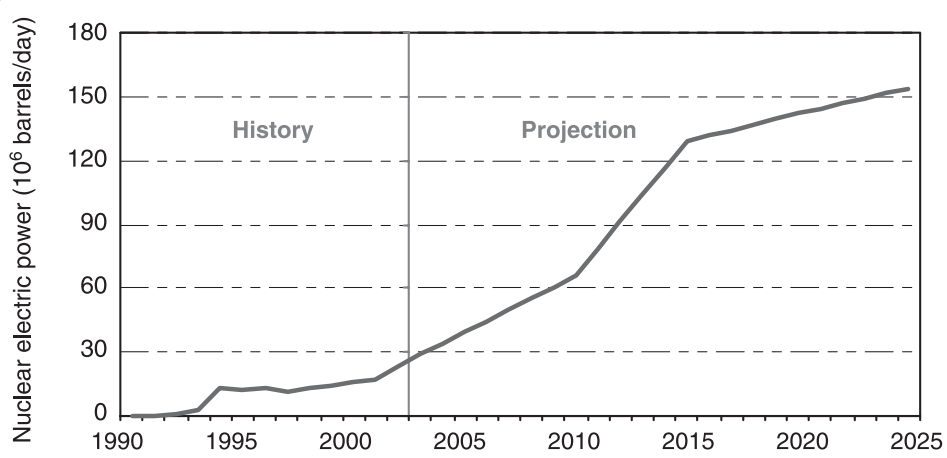

Figure 4 Projection of China's energy consumption by fuel type, 1990-2025: (a) natural gas; (b) coal; (c) petroleum; and (d) nuclear electric power. Source: Energy Information Administration (2004). 


\section{Environmental Issues related to Energy Use}

The environmental and health impacts of energy use cover a range of issues from local particulate emissions, which have important impacts within China, through acid rain, which has both local and regional impacts, to carbon dioxide emissions, which have global implications.

At the local level, a number of studies have explored air pollution caused by energy use in China. The term "air pollution" covers a wide range of problems including emissions of particulates, sulfur dioxide, nitrous oxides and carbon dioxide. The estimated costs of air pollution, largely due to the burning of fossil fuels, vary in size. A study by the World Bank (1997) valued health damages from air pollution at 5\% of GDP in 1995, ${ }^{7}$ although other studies such as Yang and Schreifels (2003) suggest this is closer to 2\% of GDP. A study by Garbaccio et al. (1999) found that a reduction in carbon emissions of $5 \%$ every year would reduce local health costs by $0.2 \%$ of GDP annually. Figure 5 shows the projection carbon dioxide emissions for China. A recent report by the State Environmental Protection Agency (SEPA) on the environment notes that air quality in cities across China has generally improved but this is from a base of significant problems in most major Chinese cities (SEPA, 2004). The World Health Organization (WHO) notes that only $31 \%$ of Chinese cities met the WHO standards for air quality in 2004 (WHO, 2004). A large part of these air quality problems is directly related to energy use. Whether the projection of rising energy use over the coming decade directly lead to projections of increased environmental problems is a critical issue facing policymakers in China. This is well understood in China. Premier Wen Jiabao in his March 5th 2005 report to the National Peoples Congress argued that improved energy conservation was necessary to reconcile rapid economic growth with limited energy resources; he also called for stronger pollution controls. SEPA, ${ }^{8}$ which

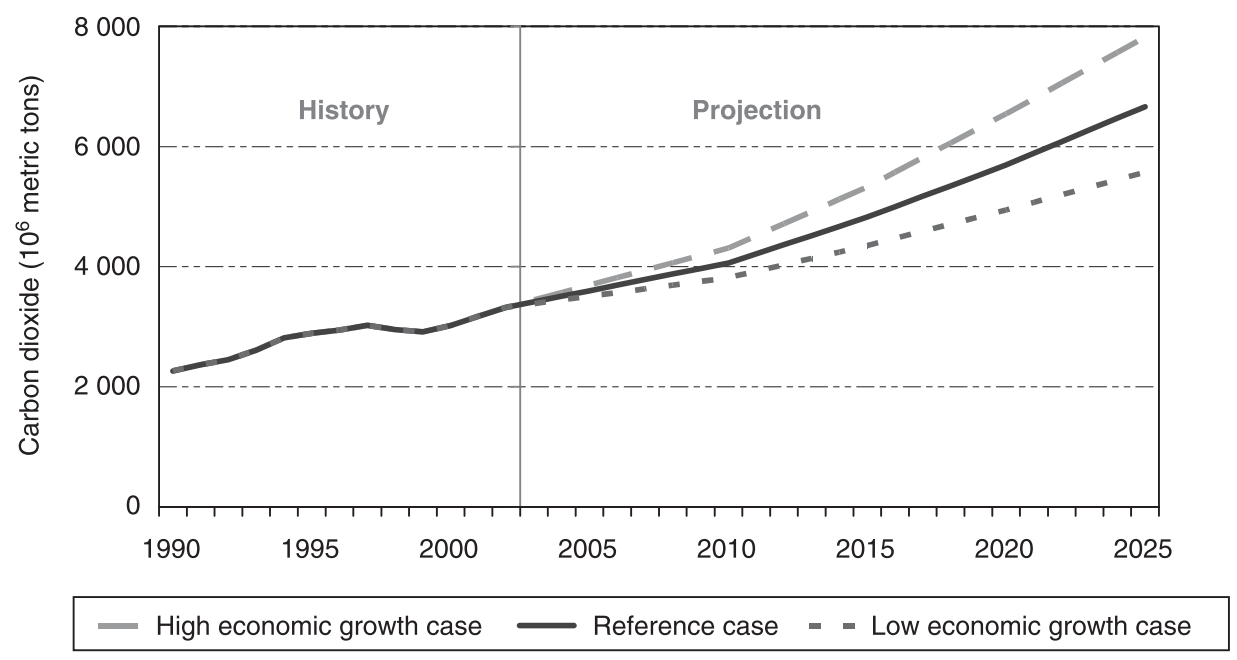

Figure 5 Projection of China's carbon dioxide emissions, 1990-2025. Source: Energy Information Administration (2004). 
was originally established in 1988 as the National Environmental Protection Agency, has also been implementing more stringent monitoring and enforcement of environmental legislation.

Particulate emissions cause serious health problems with identifiable economic costs as well as human costs. A recent study by Ho and Jorgenson (2003) found the largest sources of total suspended particulates (TSP) are the largest users of coal: electricity, non-metal mineral products and metals smelting as well as transportation.

One of the worst pollutants from burning fossil fuels is sulfur dioxide emissions. This has local (health and acid rain) as well as regional (acid rain) implications. WHO estimates that more than 600 million people are exposed to sulfur dioxide levels above the WHO standards (WHO, 2001). Sulfur dioxide mixing with nitrogen oxides causes acid rain. WHO estimates that acid rain seriously affects $30 \%$ of China (WHO, 2004, p. 6; SEPA, 2004). However, this is not just a problem for China. Streets (1997) estimates that China accounted for $81 \%$ of sulfur dioxide emissions in North-East Asia in 1990. China is the major source of acid rain across North-East Asia. Without any control policies, Streets estimated in 1997 that this share would change little by 2010 except that the quantity of emissions is expected to grow by $213 \%$ from 1990 to 2010 and by $273 \%$ to 2020 . Assuming installation of state of the art flue-gas desulfurization systems, Streets estimated that this scenario could be transformed so that sulfur dioxide emissions fall to $31 \%$ of 1990 emissions by 2020 . China has begun to address this problem with pilot sulfur dioxide emission trading systems in a number of control zones and closing of high sulfur coal mines as well as other direct controls. In fact sulfur dioxide emissions have fallen gradually from 1995 to 2002 but rose again in 2003. The decline was a result of direct controls and other policies, although acid rain problems have not fallen because of a substitution of emission towards high stack sources that spread sulfur dioxide over greater areas (Yang \& Schreifels, 2003; pp. 7-8). Direct policy to deal with sulfur dioxide emissions would seem to have a significant benefit for China and across the region and the Chinese authorities are acting on this. ${ }^{9}$ Experimentation with price-based charging and emissions trading systems have yielded encouraging results and should be used more extensively to reduce the emission of sulfur from the projected increased use of coal for generating energy in the coming decade.

A more recent and potentially more important problem identified by Streets and others (Streets, 2004; Streets et al., 2003) is the emission of black carbon. Black carbon is the term for fine particulates that are released from imperfect combustion of carbonaceous materials. Any visitors to Chinese cities are familiar with the thick haze that frequently envelopes many areas. Current work suggests that direct action to reduce the emissions of black carbon from household energy use and burning of forests and agricultural waste is an important issue that needs urgent attention in China. Understanding of black carbon emissions is only fairly recent due to the work of Hamilton and Mansfield (1991), Hansen and Sato (2001) and Streets (2004). Black carbon is classified as an aerosol and is therefore not included in the Kyoto Protocol. However, studies by Streets and others suggest it is a critical issue for China. The consequences of black carbon are wide ranging, and include reduced visibility, serious health problems and damage to buildings. Estimates suggest that agriculture crop productivity might be reduced significantly (by up to $30 \%$ for rice and 


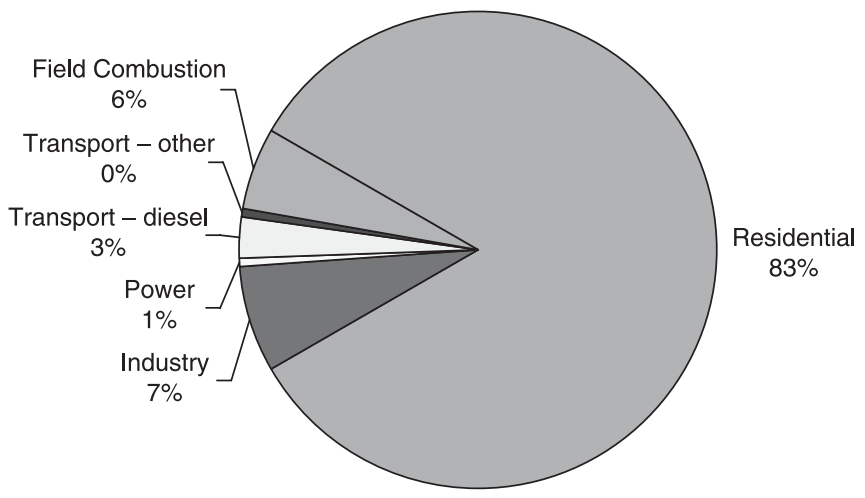

Figure 6 Sources of black carbon in China, 1995. Source: Streets (2004).

wheat). ${ }^{10}$ Streets (2004; p. 3) argues that black carbon is the second most important warming agent behind carbon dioxide. Using circulation models, Menon et al. (2002) estimate that black carbon is responsible for local climate problems in China, such as increased drought in northern China and summer floods in southern China. The time lag between reducing black carbon emissions and significant local climate effects is estimated to be around five years; a far quicker effect on climate than the implications of tackling carbon dioxide emissions, which are measured in many decades.

The estimated sources of black carbon are contained in Figure 6. Surprisingly a vast majority of emissions are from residential energy use rather than electricity generation or transportation. Residential burning of coal accounted for $83 \%$ of emissions in 1995 . This is due to the fact that $80 \%$ of Chinese households use solid/biomass fuels for cooking and heating (WHO, 2004). Thus black carbon is likely to be an important issue that authorities are yet to tackle. Part of the reason is that it is a relatively recently understood problem and partly because the solution does not lie in the energy generation sectors but in the use of energy by households.

There are a number of significant environmental problems associated with energy use in China. These have had large economic costs in the past. With the enormous expected rise in energy use in China over coming decades outlined in Section 2, the environmental problems associated with rising Chinese energy use is going to be accentuated. Policies aimed at these problems will need to broaden in scale and scope. Although existing problems are beginning to be tackled, new problems such as global climate change are emerging and China, due to its size and speed of economic growth, is a major player at the global level.

\section{Responding to Energy Related Environmental Challenges}

China has begun to respond to the local environmental problems associated with rising energy use. These include an attempt to substitute non-fossil fuel energy sources such as wind, hydro and thermonuclear energy for fossil fuels in energy generation. China has also implemented a range of policies to reduce the emissions of sulfur dioxide from burning 
fossil fuels. The problem of black carbon was discussed in the previous section. From a global perspective the one area where China has taken less action is in the emissions of carbon dioxide. This is the focus of this section.

The most important cause of human induced climate change is the accumulation of greenhouse gases in the atmosphere. The most important greenhouse gas is carbon dioxide. The global community has been struggling with how to effectively respond to the threat of climate change for several decades. In 1992, the United Nations Earth Summit in Rio de Janeiro produced a landmark treaty on climate change that undertook to stabilize greenhouse gas concentrations in the atmosphere. By focusing on stabilization, however, the treaty implicitly adopted the position that the risks posed by climate change require that emissions be reduced no matter what the cost. The agreement, signed and ratified by more than 186 countries, including the USA and China (the world's largest carbon dioxide emitters), spawned numerous subsequent rounds of climate negotiations aimed at rolling back emissions from industrialized countries to the levels that prevailed in 1990. To date, however, the negotiations have had little effect on greenhouse gas emissions and have not produced a detectable slowing in the rate of emissions growth. ${ }^{11}$ The treaty's implementing protocol, the 1997 Kyoto agreement, has crawled to life after being heavily diluted at subsequent negotiations in Bonn and Marrakech. ${ }^{12}$ The Kyoto Protocol entered into force on 16 February 2005 after ratification by Russia, yet there are a still many problems to be faced before it will be evident that Kyoto is actually reducing emissions. More than a decade of negotiations has produced a policy that is very strict in principle but is likely to be ineffective in practice.

The problem at the international level is actually worse than it appears from the troubled process of Kyoto ratification. The Kyoto Protocol only places restrictions on the industrial economies excluding the world's largest greenhouse emitter, the USA. Developing countries, including China, have ratified the agreement but have not taken on any responsibilities for reducing emissions except those that emerge from mechanisms such as the Clean Development Mechanism (CDM) and joint implementation (JI). That developing countries are not taking on targets as commitments is one of the reasons claimed by both the USA and Australia for not ratifying the Kyoto Protocol. The fact that the world's largest emitter, the USA, is not involved in climate policy substantially dilutes global action even further. Because there are no binding commitments by the key developing countries of China, India, Brazil and Indonesia (among others) means that effective action against possible climate change is still a hypothetical debate.

Developing countries have a valid point in their argument that while they are prepared to be part of a regime to tackle climate change, they should not be required to bear a disproportionate part of the costs of taking action. Current concentrations of greenhouse gases in the atmosphere are primarily the result of economic activities in the industrial economies since the Industrial Revolution. Because it is the stock of carbon in the atmosphere that matters for temperature changes, any climate change in the near future will be largely the result of the historical activities of industrial economies. Why should developing countries not be able to follow the same energy intensive development paths of the currently industrialized economies? The answer to this question has inevitably led to an expectation of 
compensation paid for by the industrialized economies for action taken in developing countries. One of the biggest dilemmas for developing countries is not just the reality that at some stage they need to make some form of commitment to curbing greenhouse gas emissions but the fact that most estimates of the damages from climate change are borne by developing countries (see IPCC, 2001).

Standing back from the intensity of international negotiations it is worth clarifying several important facts about the costs and benefits of climate policy and exploring whether there are approaches possible in China and other developing countries that are not being considered because of the standard refrain that "Kyoto is the only game in town". This mindset has already hindered effective action for the past decade as countries and industries postpone action until agreements are clarified. Given the uncertainties of climate change and the decisions on energy systems being made in the regions of the developing world that are growing rapidly, this delay in providing clear incentives for moving away from fossil fuel based systems, may ultimately prove to be extremely costly.

One of the largest sources of anthropogenic greenhouse gas emissions is the burning of fossil fuels. The cheapest means of changing the global energy system so that it is less reliant on fossil fuels is to remove these emissions from future energy systems rather than from existing energy systems. As shown in Section 2, China is heavily reliant on coal for energy production and is likely to be for many decades to come. There are huge investments in physical and human capital surrounding existing energy systems, which are costly to change. However, future investments (largely to occur in developing countries) are much cheaper to change before they are undertaken. Technology will ultimately be the source of reductions in emissions whether through the development of alternative sources of energy or through ways of sequestering carbon released from burning fossil fuels. Developing countries have huge potential to avoid the pitfalls in terms of carbon intensities experienced by industrialized economies in their development process. The key issue is how to encourage the emergence of energy systems in developing countries that are less carbon intensive over time. Ultimately if climate change does emerge as a serious problem, developing countries will have to move towards a less carbon intensive future. It is likely to be significantly cheaper to do this over time than to face a massive restructuring at some future period: the sort of problems being faced within industrialized economies today.

The current state of global policy on climate is that the USA (the largest emitter of greenhouse gases) has rejected Kyoto and is arguing for following policies that directly or indirectly reduce emissions through technological change; the European Union is committed to emission targets (assuming Russia provides a great deal of those reductions required through selling emission permits) and has implemented a Europe-wide emissions trading scheme (that exempts key sectors such as aluminum, motor vehicles and chemicals) on 1 January 2005, but with actual caps that appear only to bind by the end of 2008; Japan is considering what it can do given current emissions are $16 \%$ above target in an economy recovering from a decade of recession; and developing countries have refused to officially discuss taking on commitments.

Given this background, there are a number of ways a country such as China could begin to address carbon emissions and make a major contribution to a global response. 
One step would be the removal of energy subsidies. The second would be to further raise the price of energy to reflect the true economic and environmental cost of burning fossil fuels. Another approach could be direct importation of less carbon intensive technologies provided by the CDM. This latter outcome is possible but not likely as already outlined above. Thus the focus here will be on the other alternatives.

Economic theory provides guidance about the structure of a possible climate change policy for China. ${ }^{13}$ As greenhouse gases are emitted by a vast number of highly heterogeneous sources, minimizing the cost of abating a given amount of emissions requires that all sources clean up amounts that cause their marginal cost of abatement to be equated. To achieve this, the standard economic policy prescription would be a market-based instrument, such as a tax on emissions or a tradable permit system for emission rights. This type of market-based incentives for environmental pollution is already being undertaken in China through pollution charges and permit trading in sulfur dioxide. Cooper (2005) has advocated a carbon tax for China. Garbaccio et al. (1999) and McKibbin and Wilcoxen (2004) found that a price signal would be effective in changing China's future emissions profiles. In the absence of uncertainty, the efficient level of abatement could be achieved under either a tax or a permit trading system, although the distributional effects of tax and emissions trading policies would be very different.

Under uncertainty, however, the situation becomes more complicated. Weitzman (1974) showed that taxes and permits are not equivalent when marginal benefits and costs are uncertain, and that the relative slopes of the two curves determine which policy will be better. ${ }^{14}$ Emission permits are better than taxes when marginal benefit schedules are steep and marginal costs are flat: in that situation, it is important to get the quantity of emissions down to the threshold. A permit policy does exactly that. In the opposite situation, when marginal costs are rising sharply and marginal benefits are flat, a tax would be a better policy. The potential inefficiency of a permit system under uncertainty is not just a theoretical curiosity: it is intuitively understood by many participants in the climate change debate by the expression of the concern about a policy that "caps emissions regardless of cost."

Applying this analysis to climate change shows that a tax is likely to be far more efficient than a permit system under the uncertainties surrounding climate change. All evidence to date suggests that the marginal cost curve for reducing greenhouse gas emissions is very steep, at least for developed countries. Although there is considerable disagreement between models on how expensive it would be to achieve a given reduction in emissions, all models show that costs rise rapidly as emissions targets become tighter. At the same time, the nature of climate change indicates that the marginal benefit curve for reducing emissions will be very flat.

Given the advantages and disadvantages of the standard economic instruments, is it possible to combine the attractive features of both systems into a single approach? Second, is it possible to develop a system that is common in philosophy across developed and developing economies but in which developing economies do not incur the short-run costs to the economy in the form of higher energy prices until they have reached a capacity to pay?

There are a number of goals that should be at the core of any climate change regime. These involve the recognizing the trade-off between economic efficiency and equity within 
and between countries. The policy should also be based around clear property rights over emissions and clear long-run emission targets but near certainty in the short-run costs to the economy. A sensible climate policy should also create domestic institutions that allow people to self-insure against the uncertainties created by climate change. There should be market mechanisms that give clear signals about the current and expected future costs of carbon. There should be coalitions created within countries with the self-interest of keeping climate change policy from collapsing rather than creating a system of international sanctions in order to sustain the system.

The McKibbin-Wilcoxen Blueprint (see McKibbin \& Wilcoxen, 2002a; 2002b) was created to attempt to explicitly deal with these issues. It is a hybrid system that blends the best features of taxes and emission permit trading. ${ }^{15}$ It is a system that can be applied across developed and developing countries but that recognizes that developing countries should not bear the same economic costs as industrial countries in the short run.

Although set out in detail in McKibbin and Wilcoxen (2002a) the approach can be briefly outlined here. The basic idea is to impose a requirement that energy producers have an annual emission permit to produce energy each year, based on the carbon content of that energy. A fixed quantity of long-term permits would be created that allow a unit of emission every year for 100 years. These long-term permits are traded in a market with a flexible price. The government would also be able to create additional annual permits in any year at a guaranteed price. Permits that satisfy the annual constraint for energy production can be either a long-term permit or an annual permit that is provided by the government at a fixed price. The price of emissions in any year would never be higher than the fixed price set by the government and the amount of emissions in any year would be whatever the market delivers. Thus we have a long-term target in terms of emissions but an annual target in terms of the maximum cost of carbon to industry. In a developing country such as China, the annual price would initially be zero if we allow an allocation of long-term permits well in excess of current emissions. However, the price of long-term permits would reflect the expectation that China would eventually reach the emission levels that caused the carbon emission constraint to be binding. Thus the market for long-term permits with positive prices would provide a financial incentive to begin to change Chinese carbon emissions over time even though the annual cost to industry of a carbon permit would initially be zero.

McKibbin and Wilcoxen (2002a) argue that the allocation of long-term permits would be determined by each country. The long-term permits could be auctioned, in which case the permits are actually a tax. The long-term permits could be given away to existing carbon emitters in which case the permits are a way of grandfathering or compensating existing emitters. The allocation mechanism of long-term permits is a wealth transfer that has little impact on the subsequent economic incentives facing emitters of greenhouse gases.

The attractiveness of the Blueprint for creating institutions to aid in economic development in a developing country like China should not be underestimated. The ability of investors in energy systems to effectively hedge their investment over a long period of time should be very attractive for the development of energy systems in developing countries. The timeframe of the assets we propose to be created (by committing to a global climate 
regime) is currently unparalleled. China could use this new asset as a way of attracting foreign investment and enhancing the development process by creating what is effectively a futures market in energy (for example by not allocating all long-term permits to current emitters by holding a reserve for foreign investors). This is far more likely to induce foreign investment than the CDM or other similar mechanisms that face very high administrative costs. Critics might argue that the problem with China is the inability to create the sorts of institutions the above scheme would require. This is a problem in the near term but it is easier for China to create property rights and institutions within China according to the philosophy and characteristics of China, than it would be to impose within China the sorts of institutions and property rights based on Western approaches that would be required under the Kyoto Protocol for China to be able to sell carbon rights into a global markets. The required synchronization of property rights globally in a form reflecting developed countries practices is exactly why it is difficult to see how the Kyoto Protocol could be implemented outside the small group of industrialized countries with similar institutional structures that are already involved.

\section{Policy Implications and Conclusion}

Environmental degradation, particularly related to energy use, raises a number of important issues for Chinese policymakers. With high economic growth and rising energy needs expected to continue over coming years, addressing many of these issues is important. This is particularly true given that energy systems are currently being developed and will be locked into place for many decades into the future. This paper has demonstrated that China is already a large country in terms of resource use, and regional and global environmental impacts.

The problem of black carbon and its direct health, economic and environmental consequences is a promising area for close attention and direct policy intervention. This is not an issue of technological change at the power utilities as might usually be the focus of energy policy. A reduction in the emissions of black carbon will require a technology shift in the way households generate heating and cooking and in the way farmers clear their land after harvest. It appears that it would be feasible to implement a phase-in of alternative technologies at the household level over coming years with the potential to generate a range of environmental, health and economic benefits. Addressing black carbon is a good candidate for consideration under the "Asia Pacific Partnership for Clean Development and Climate" announced on 28 July 2005, which consists of the USA, Japan, Australia, South Korea, China and India. Black carbon is an aerosol and therefore is not covered by the Kyoto Protocol and the payoffs for taking action in both development terms and climate outcomes are likely to be large and achieved within a decade.

China has already started to take action to reduce emissions of sulfur by substituting away from high sulfur coal, by closing small, high sulfur coal mines, with direct controls on sulfur dioxide emissions, implementation of pilot schemes for sulfur dioxide emission charges and pilot schemes for sulfur dioxide emissions trading. These are having an impact on emissions of sulfur although the impact on acid rain has been less clear. As Nakada and 
Ueta (2004) point out, there are likely to be gains for other economies in the region such as Japan and Korea to cooperate with China in controlling sulfur emissions, as these economies are also directly affected by acid rain emanating from China.

At the global level the emissions of carbon dioxide from burning fossil fuels is yet to be effectively addressed in China; or in most other countries. Even if rapid action was possible, the payoff in terms of potential climate change will not be realized for many decades into the future. Although some researchers believe that a global response, such as that of the CDM of the Kyoto Protocol, is one way to proceed (see Ueta et al., 2005), it is doubtful that much can be achieved through this approach alone. A strong case can also be made for responses to be developed within China to carbon dioxide emissions. Potential exists for experimenting with hybrid market/government control schemes such as the McKibbinWilcoxen Blueprint in which important institutions are created to begin a long process of reduced carbonization of the Chinese economy. This would allow China to continue to grow but would put in place a pricing mechanism for future carbon emissions as an incentive to gradually shift Chinese energy systems to low carbon emitting technologies. The creation of institutions for environmental management, particularly through market incentives, between now and 2010 will be the most important steps to be taken in China. The demonstration effect of such an approach could have an even bigger impact of global emissions if it encouraged other developing countries and the USA to begin to price carbon more appropriately given the current state of knowledge about the potential of climate change.

The problems of energy generation and environmental impacts of energy use over coming decades are varied in nature and require a variety of responses ranging from direct government intervention, technical innovation, and creating incentives for changing consumer and producer behavior in China. The sooner these issues are addressed the better because decisions made in the next decade in China will influence the nature of the energy system in China and potentially the rest of the world for many decades into the future.

\section{Notes}

1 All data are sourced from the Energy Information Administration (2004) of the US Department of Energy and are for 2004 unless specifically indicated otherwise.

2 There are many other environmental problems caused by a large population and rapid economic growth in China, such as water quality and air quality problems caused by deforestation and desertification. China's demand for resources also has a large impact on the environment of other countries. These important problems are not the subject of this paper but for an overview see Liu and Diamond (2005).

3 China's Environmental Protection Law was promulgated in 1979; a nationwide levy system on pollution began in 1982. Fees for sulfur dioxide pollution from coal began being collected in 1992. See Jiang (2003) for an overview.

4 Further details on the Kyoto Protocol can be found in section 4 .

5 See Jiang (2003) for an overview of China’s environmental problems. Jiang and McKibbin (2002) found that Chinese policy has been effective in reducing environmental problems relative to what would otherwise be the case, but other factors related to strong economic growth have offset and masked this improvement. Also see Panayatou (1998). 
6 A large body of literature on using PPP for energy inter-country comparisons is summarized in Castles and Henderson (2003).

7 Panayotou and Zheng (2000) estimate that the cost to China from air and water pollution is $14.6 \%$ of GDP in the late 1990s. Also see Wang and Smith (1999).

8 The formerly named National Environmental Protection Agency was set up in 1988 and renamed SEPA in 1998 when it was upgraded to a Ministry.

9 Nakada and Ueta (2004) estimate that the current sulfur price is well below the socially optimal price.

10 See Streets (2004) and the reference therein.

11 See McKibbin and Wilcoxen (2002) for a summary of the negotiations and critique of the approach.

12 Earlier estimates of the cost of the Kyoto Protocol can be found in Weyant (1999). Direct comparisons of the COP3 and COP7 versions of the protocol can be found in Bohringer (2001), Buchner et al. (2001), Kemfert (2001), Löschel and Zhang (2002) and McKibbin and Wilcoxen (2004).

13 See McKibbin and Wilcoxen (2002a) for a survey and Pezzey (2003) for a comparison of taxes and permits.

14 See also Pizer (1997) for a more recent discussion of the issue.

15 The intellectual idea actually dates back to Roberts and Spence (1976) for general environmental policy and McKibbin and Wilcoxen (1997) for climate change policy.

\section{References}

Bagnoli P., McKibbin W., Wilcoxen P. (1996). Future projections and structural change. In: Nakicenovic N., Nordhaus W., Richels R., Toth F. (eds), Climate Change: Integrating Economics and Policy, CP 96-1, Vienna: International Institute for Applied Systems Analysis, 181-206.

Bohringer C. (2001). Climate policies from Kyoto to Bonn: From little to nothing? Discussion Paper No. 01-49, ZEW Mannheim.

Buchner B., Carraro C., Cersosimo I. (2001). On the consequences of the US withdrawal from the Kyoto/Bonn Protocol. Paper presented at the 17th Annual Congress of the European Economic Association, Venice, August 2002.

Castles I., Henderson D. (2003). The IPCC emission scenarios: An economic-statistical critique. Energy \& Environment 14, 159-185.

China Council for International Cooperation on Environment and Development (2001). Report of Environmental Working Group. Beijing: China Council for International Cooperation on Environment and Development.

Cooper R. (2005). A Carbon Tax in China? Washington, DC: Climate Policy Center.

Department of Energy (2004). An Energy Overview of the People's Republic of China. Washington, DC: Department of Energy. Available from: http://www.fe.doe.gov/international/ EastAsia_and_Oceania/chinover.html

Energy Information Administration (2004). International Energy Outlook. Washington, DC: Department of Energy.

Garbaccio R.F., Ho, M.S., Jorgenson D.W. (1999). Controlling carbon emissions in China. Environment and Development Economics 4, 493-518.

Hamilton R.S., Mansfield T.A. (1991). Airborne particulate elemental carbon: its sources, transport and contribution to dark smoke and soiling. Atmosphere and Environment 25, 715-723. 
Hansen J.E., Sato M. (2001). Trends of measured climate forcing agents. Proceedings of the National Academy of Science USA 98, 14778-14783.

Ho M., Jorgenson D. (2003). Air Pollution in China: Sector Allocation Emissions and Health Damage. Beijing: China Council for International Cooperation on Environment and Development.

Intergovernmental Panel on Climate Change (IPCC) (2001). Climate Change 2001. Cambridge: Cambridge University Press.

International Monetary Fund (2004). World Economic Outlook. Washington: International Monetary Fund.

Jiang T. (2003). Economic Instruments of Pollution Control in an Imperfect World. Cheltenham UK: Edward Elgar.

Jiang T., McKibbin W. (2002). Assessment of China's pollution levy system: An equilibrium pollution approach. Environment and Development Economics 7, 75-105.

Kemfert C. (2001). Economic effects of alternative climate policy strategies. Environmental Science and Policy 5, 367-384.

Liu J., Diamond J. (2005). China's environment in a globalizing world. Nature 435, 11791186.

Löschel A., Zhang Z.X. (2002). The economic and environmental implications of the US repudiation of the Kyoto Protocol and the subsequent deals in Bonn and Marrakech. Nota Di Lavoro 23.2002, Venice: Fondazione Enie Enrico Mattei, April.

Menon S., Hansen J., Nazarenko L., Luo Y. (2002). Effects of black carbon aerosols in China and India. Science, 297, 2250-2253.

McKibbin W., Pearce D., Stegman A. (2004). Long run projections for climate change scenarios. Working Paper in International Economics, The Lowy Institute for International Policy.

McKibbin W.J., Wilcoxen P.J. (1997). A better way to slow global climate change. Brookings Policy Brief 17 (June). Washington DC: The Brookings Institution.

McKibbin W.J., Wilcoxen P.J. (2002a). Climate Change Policy after Kyoto: A Blueprint for a Realistic Approach. Washington, DC: The Brookings Institution.

McKibbin W.J., Wilcoxen P.J. (2002b). The role of economics in climate change policy. Journal of Economic Perspectives 16, 107-130.

McKibbin W.J., Wilcoxen P.J. (2004). Estimates of the costs of Kyoto-Marrakesh versus the McKibbin-Wilcoxen blueprint. Energy Policy 32, 467-479.

Nakada M., Ueta K. (2004). Sulfur emissions control in China: Domestic or regional cooperative strategies? 21COE Discussion Paper 41, Kyoto University.

National Bureau of Statistics (2003). China Statistical Yearbook 2003. Beijing: China Statistics Press.

Panayotou T. (1998). The effectiveness and efficiency of environmental policy in China. In: McElroy M., Nielsen C., Lydon P. (eds), Energizing China, Reconciling Environmental Protection and Economic Growth. Boston: Harvard University Press, 431-472.

Panayotou T., Zheng X. (2000). The Cost of Environmental Damage in China: Assessment and Valuation Framework. Beijing: China Council for International Cooperation on Environment and Development.

Pezzey J. (2003). Emission taxes and tradable permits: a comparison of views on long run efficiency. Environmental and Resource Economics 26, 329-342.

Pizer W.A. (1997). Prices versus Quantities Revisited: The Case of Climate Change. Discussion Paper 98-02. Washington, DC: Resources for the Future.

Roberts M.J., Spence A.M. (1976). Effluent charges and licenses under uncertainty. Journal of Public Economics 5, 193-208. 
State Environmental Protection Agency (SEPA) (2004). Report on the State of the Environment in China: 2003. Beijing: SEPA.

Streets D.G. (1997). Energy and Acid Rain Projections for North East Asia. San Francisco: The Nautilus Institute. Available from: http://www.nautilus.org/archives/papers/energy/streetsESENAY1.html

Streets D.G. (2004). Black smoke in China and its climate effects. Paper presented to the Asian Economic Panel, Columbia University.

Streets D.G., Bond T.C., Carmichael G.R. et al. (2003). An inventory of gaseous and primary aerosol emissions in Asia in the year 2000. Geophysical Research 108, 8809.

Ueta K., Inada Y., Fujikawa K. et al. (2005). Win-win strategy for Japan and China in climate change policy. Report to the International Collaborations Project on Sustainable Societies.

UNDP (2004). Human Development Report. Geneva: United Nations.

Wang X., Smith K. (1999). Secondary benefits of greenhouse gas control: Health impacts in China. Environmental Science and Technology 33, 3056-3061.

Weitzman M.L. (1974). Prices versus quantities. Review of Economic Studies 41, 477-91.

Weyant J. (ed.) (1999). The costs of the Kyoto protocol: A multi-model evaluation. The Energy Journal, Special Issue.

World Bank (1997). Clear Water, Blue Skies: China's Environment in the New Century. Washington, DC: World Bank.

World Health Organization (WHO) (2001). Environment and Peoples' Health. Geneva: WHO and UNDP.

World Health Organization (WHO) (2004). Environmental Health Country Profile: China. Geneva: WHO.

Wu L., Kaneko S., Matsuoko S. (2003). Driving forces behind the stagnancy of China's energy related $\mathrm{CO}_{2}$ emissions from 1996 to 1999: The relative importance of structural change, intensity change and scale change. Energy Policy 31.

Yang J., Schreifels J. (2003). Implementing $\mathrm{SO}_{2}$ emissions in China. In: OECD Global Forum on Sustainable Development: Emissions Trading. Paris: OECD. 